\title{
A PARTICIPAÇÃO DA SOCIEDADE E O CASO DA POLÍTICA NACIONAL DE EDUCAÇÃO ESPECIAL NA PERSPECTIVA DA EDUCAÇÃO INCLUSIVA: REFLETINDO SOBRE A FORMAÇÃO DE PROFESSORES
}

\section{PARTICIPATION OF THE CIVIL SOCIETY AND THE CASE OF THE BRAZILIAN NATIONAL POLICY FOR SPECIAL EDUCATION IN THE INCLUSIVE EDUCATION PERSPECTIVE: REFLECTING ON TEACHERS' EDUCATION}

\author{
Manoella Senna ${ }^{94}$ \\ Mônica Pereira dos Santos ${ }^{95}$ \\ Lidiane Moraes Buechen Lemos ${ }^{96}$
}

\begin{abstract}
Resumo
O presente artigo pautou-se na questão: como vem se organizando o campo da educação especial na perspectiva da inclusão em educação à luz da proposta de "atualização" por parte do governo federal brasileiro, da Política Nacional da Educação Especial na Perspectiva da Educação Inclusiva? Apresentamos um breve panorama do campo da educação especial, seguido da discussão sobre políticas nacionais e internacionais que embasam essa modalidade de ensino. Discutimos que as propostas com relação à atualização da atual PNEEPEI, apresentam-se como um retrocesso para o campo da inclusão em educação, tendo em vista a ausência de diálogo e participação da sociedade em sua elaboração. Além disso, foram apontados alguns desafios para a formação de professores para esse campo.
\end{abstract}

Palavras-chave: Educação Especial. Inclusão em Educação. Políticas de Inclusão.

\begin{abstract}
This article focused on the question: how has the field of special education been organized in the perspective of inclusion in education in the light of the proposal of "updating" the National Policy of Special Education in Perspective of Inclusive Education by the Brazilian national government,? We present a brief overview of the field of special education followed by a discussion of the national and international policies that underlie this modality of teaching. We argue that the proposals regarding the "updating" of the current PNEEPEI were being perceived as a step backward to inclusion in education, in view of the absence of dialogue and

\footnotetext{
94 Doutoranda em Educação (PPGE/UFRJ). Mestra em Educação (PPGE/UFRJ). Universidade Federal do Rio de Janeiro (UFRJ). Orientadora Educacional na Associação Educacional Garriga de Menezes. Email: manoellasenna@gmail.com. ORCID: https://orcid.org/0000-0002-4656-0359.

95 Professora Associada do Departamento de Fundamentos da Educação/Faculdade de Educação. Universidade Federal do Rio de Janeiro (UFRJ). E-mail: monicapes@gmail.com. ORCID: https://orcid.org/0000-0002-70577804.

${ }^{96}$ Graduanda em Pedagogia. Universidade Federal do Rio de Janeiro (UFRJ). E-mail: lidianebuechen@gmail.com. ORCID: https://orcid.org/0000-0001-5730-8709.
} 


\section{RevistAleph}

participation of society in its elaboration, to say the least. In addition, some challenges for teacher education for this field were pointed out.

Keywords: Special Education. Inclusion in Education. Inclusion Policies.

\section{Introdução}

O presente artigo tem por objetivo principal realizar uma análise circunstanciada de uma questão da educação contemporânea, dentro da temática da educação especial, apresentando uma reflexão acerca da participação da sociedade na proposta de reformulação da PNEEPEI tendo em vista seus desdobramentos para a formação de professores. Para tanto, nos pautamos em algumas questões que nortearão nossas reflexões: como vem se organizando o campo da educação especial na perspectiva da educação inclusiva à luz da proposta de "atualização", por parte do governo, da Política Nacional da Educação Especial na Perspectiva da Educação Inclusiva - PNEEPEI (BRASIL, 2008)? Quais processos e movimentos têm sido costurados nesse campo? Como tem se dado a participação da sociedade civil e da universidade nesses processos? Quais os desafios para a formação de professores no que tange a esse campo?

Com o intuito de discutir as questões apresentadas, como objetivos específicos esse artigo se propõe a: apresentar um breve panorama do campo da educação especial; apresentar e discutir sobre as políticas internacionais e nacionais que embasam essa modalidade de ensino nacionalmente, demonstrando os embates e lutas deste campo que têm sido citados e travados na contemporaneidade; refletir sobre a participação da sociedade, discutindo alguns desafios para a formação de professores no que tange à educação especial.

A escolha pela discussão da temática da educação especial baseia-se em três pontos. Primeiro, destacamos a importância dos movimentos políticos e as disputas existentes em seu campo que proporcionam debates com relação ao processo de inclusão das pessoas com deficiência na escola. Ao longo dos anos, vimos observando a força de movimentos da sociedade (famílias, associações de caráter filantrópicos-assistenciais, profissionais e pesquisadores do campo) na construção e modificação das políticas que orientam as ações com relação à inclusão do aluno com deficiência na sala de aula regular, demonstrando que sua participação nesse processo tem trazido contribuições fundamentais para o campo da educação especial (PLETSCH, 2014). 


\section{RevistAleph}

Além disso, o campo da educação especial, como qualquer outro, apresenta nuances que o faz, por vezes, em termos de culturas, políticas e práticas, apresentar-se ora em avanços, ora em recuos. Isso porque, tendo em vista as diferentes posições (teóricas e práticas) de como deve se organizar essa modalidade, as lutas que ensejam o processo de construção de políticas educacionais são inúmeras, e representam interesses políticos governamentais, interesses das famílias, dos educadores e pesquisadores da área. Outro motivo para a escolha deste tema foi o movimento do Ministério da Educação, ainda no governo Temer, em 2018, de realizar mudanças na atual política nacional que rege a educação especial na perspectiva da educação inclusiva e que tem promovido posicionamentos, principalmente o de pesquisadores sobre a temática, com preocupações de que tais mudanças levem a retrocessos relativos à inclusão de alunos com deficiência, ou seja, que desfaçam conquistas já estabelecidas no campo.

No que tange ao campo da formação de professores, vale destacar que nos situamos na argumentação apresentada por Saviani (2007) e Cruz (2012), de modo a reforçar a importância do debate epistemológico da pedagogia e da formação de professores. Isso porque quando pensamos no campo da educação especial, também há disputas sobre como deva ser a formação do professor, seja ele da sala de aula comum ou do Atendimento Educacional Especializado (AEE), formado em nível de graduação ou de especialização, disputas essas importantes para a compreensão e formação na área, e para tanto, nos basearemos também em Santos, Santiago e Melo (2015; 2019).

\section{Breve histórico: educação especial e inclusão em educação}

De acordo com Kassar (2012), falar sobre educação especial no Brasil pressupõe falar de desigualdade e diversidade, já que o Brasil, ao mesmo tempo que tão vasto e diverso, tem um histórico de uma grande maioria da população sem acesso a condições de vida minimamente satisfatórias. Até meados do século XX, no conjunto de populações marginais (condições de vida e de pobreza) encontravam-se também pessoas com deficiências. Inicialmente, ligados a uma visão médica e, portanto, clínica, os atendimentos a essa população eram feitos por iniciativas particulares isoladas, já que o Estado parecia se omitir dessa função. Em termos de atendimentos educacionais, havia forte movimento de 


\section{RevistAleph}

patologização e separação dos alunos por características, usadas para Ihes justificarem rótulos como "anormais" (PLETSCH, 2014; KASSAR, 2012).

Entre os anos 50 e 90 foi crescente o movimento de iniciativas oficiais no âmbito nacional com relação ao atendimento das pessoas com deficiência em termos de educação, ao encontro da também crescente força dos movimentos da sociedade (família e instituições filantrópicas). Neste período apareceram as campanhas nacionais e foram criadas secretarias para o acompanhamento no país da educação desse grupo. Embora em termos de políticas públicas o movimento do governo tenha sido fundamental, destacamos a importância do movimento de instituições como Instituto Benjamin Constant (IBC), Instituto Nacional de Educação de Surdos (INES), Associação de Pais e Amigos dos Excepcionais (APAE) já que:

[...] o surgimento dessas entidades teve papel decisivo na constituição da área da Educação Especial [...] Com efeito, o surgimento dessas instituições se deu pela omissão do Estado em garantir os direitos sociais dessas pessoas pela via pública o que obrigava suas famílias a recorrerem a instituições de caráter filantrópico-assistenciais (PLETSCH, 2014, p.74).

Segundo Kassar (2012), a partir dos anos 90, principalmente, a educação no país passa por um movimento de universalização em termos de matrículas. Nesse momento, as matrículas dos alunos público alvo da educação especial crescem também (classe especial, escola especial, escola pública ou privada). Políticas internacionais e nacionais voltam seus olhares para grupos antes excluídos, demandando mudanças nas práticas educacionais e um olhar atento às diferenças e à diversidade. Ao público alvo da educação especial foram elaboradas políticas educacionais que orientam o país, conforme discutiremos na próxima seção do artigo.

Nesse sentido, observamos uma mudança de paradigmas com relação ao atendimento educacional das pessoas com deficiência no país. Inicialmente havia um movimento de total exclusão, no qual marginalizadas, as pessoas com deficiência não eram percebidas com os mesmos direitos das pessoas chamadas "normais". Após movimentos isolados de iniciativas particulares e movimentos governamentais, pessoas com deficiência começaram a frequentar o ambiente escolar, porém, em uma perspectiva, ainda, bastante segregadora, na qual os atendimentos eram feitos separadamente, em ambientes especiais.

Com as lutas e movimentos, essa visão segregadora foi substituída por uma visão de normalização e padronização que compreendia a necessidade de todos estarem juntos na 


\section{RevistAleph}

escola, chamada de integração. Desse modo, as pessoas com deficiências foram integradas à escola comum. Porém, tal fato não se mostrou ainda consistente, já que estar junto na mesma classe não representa necessariamente que todos estão aprendendo e participando como se busca, por exemplo, em uma perspectiva de inclusão. Nesse sentido, a visão de inclusão em educação foi ganhando força e demonstrando a importância do olhar para as diferenças e para a diversidade, considerando as especificidades de cada sujeito.

Segundo Santos (2002), embora diferentes em termos conceituais, tanto a educação especial quanto a inclusão em educação (com prefere chamar educação inclusiva) não devem ser separadas, mas sim compreendidas como partes de um mesmo processo histórico. Para a autora, os conceitos de integração e inclusão, respectivamente, vêm de um mesmo processo de lutas de pensar o direito à educação para todos. Com a Declaração de Salamanca, para Santos (2002), houve uma redefinição da educação especial, em termos de seu alunado e também de foco de ação, que passou a contemplar um olhar para aqueles que porventura estivessem passando por uma barreira à aprendizagem e/ou à participação, além de compreender a necessidade da mudança na organização do ambiente escolar para adequarse às necessidades dos sujeitos e não ao contrário.

Algum tempo depois, entretanto, a autora entendeu que sua análise acerca desta Declaração esteve equivocada. Em primeiro lugar, ela tem defendido inclusão em educação como um processo que, no curso da história da educação, não se constituiu em continuidade, mas em ruptura de um paradigma que defendida a ideia de que cada sujeito, para conviver com todos, deveria, primeiro, estar "pronto" - o que justificava a existência de instâncias anteriores à escola de todos (como, por exemplos, classes e escolas especiais) para alguns frequentarem até que atingissem tal "prontidão", que nunca chegava.

Deste modo, e em segundo lugar, ela passa a argumentar que os efeitos da Declaração de Salamanca foram muito mais no sentido de manter o "pool" da Educação Especial como forma paralela de educar (e muitas vezes, apenas prover assistência) às pessoas com deficiência no sistema escolar do que, efetivamente, promover a inclusão). ${ }^{97}$ Este pensamento converge com a política nacional da educação especial na perspectiva da educação inclusiva, segundo a qual:

\footnotetext{
97 SANTOS, s/d, em afirmação oral feita em reunião de trabalho do grupo de pesquisa que fundou e coordena, o LaPEADE.
} 
O movimento mundial pela educação inclusiva é uma ação política, cultural, social e pedagógica, desencadeada em defesa do direito de todos os estudantes de estarem juntos, aprendendo e participando, sem nenhum tipo de discriminação. A educação inclusiva constitui um paradigma educacional fundamentado na concepção de direitos humanos, que conjuga igualdade e diferença como valores indissociáveis, e que avança em relação à ideia de equidade formal ao contextualizar as circunstâncias históricas da produção da exclusão dentro e fora da escola (BRASIL, 2008, p. 1).

Por educação especial, portanto, compreendemos, assim como a política, uma modalidade de ensino que perpassa todos os níveis, etapas e modalidades e que por meio do Atendimento Educacional Especializado ( $A E E$ ) atende pessoas com deficiência, transtornos globais do desenvolvimento, altas habilidades/superdotação (BRASIL, 2008). Trata-se, assim, de estratégias, conhecimentos e ações para atender aos alunos com deficiência, promovendo sua aprendizagem e participação na rede regular de ensino.

Nesse sentido, vale mencionar também que compreendemos inclusão em educação com um processo cujo princípio básico é buscar "a minimização de todo e qualquer tipo de exclusão em arenas educacionais e, com isso, elevar o nível de participação, coletiva e individual de seus integrantes, ao máximo" (SANTOS \& PAULINO, 2008). Inclusão, portanto, diz respeito a colocar valores e acordos em prática que busquem sempre a participação e aprendizagem de TODOS, independente de grupos, considerando as dimensões complexas e dialéticas existente nesse processo. Compreendendo que inclusão e exclusão são processos intrínseca e dialeticamente conectados, entendemos que inclusão, assim, não é um estado final que um dia se poderá alcançar, pois sempre existirá exclusão no mundo em que vivemos, cujos pilares - por ser um mundo de base funcional capitalista - são os da exclusão (SANTOS, 2008; 2013).

Embora desde 2008, nacionalmente, tenhamos uma política da educação especial na perspectiva da educação inclusiva, tal fato não significa que esse processo não apresenta embates. Há, ainda, aqueles que lutam pela educação em classes e escolas especiais, defendendo que para determinadas deficiências esta é a única solução, enquanto há aqueles que lutam por um processo de inclusão de todos nas salas de aula regulares, apesar das dificuldades existentes na organização dessa modalidade em todos o país (ligadas a infraestrutura, investimento, formação inicial e continuada, entre outros). A respeito dessas disputas do campo é que precisamos nos atentar, pois o desenvolvimento das políticas educacionais muitas vezes reflete essas lutas e divergências de opiniões, permitindo brechas 


\section{RevistAleph}

que podem, por vezes, trazer retrocessos no que tange ao processo de inclusão, como discutiremos na próxima seção.

\section{Contexto das Políticas: educação especial na perspectiva da educação inclusiva}

Para o processo de construção da educação especial em uma perspectiva da educação inclusiva, existem algumas políticas importantes que vêm orientando as práticas educacionais. Essas políticas, consideradas como marcos legais, são de cunho internacional e/ou nacional e foram desenvolvidas em contextos de lutas e disputas políticas e sociais, refletindo os interesses das agendas de governos e da sociedade de seus tempos e espaços.

Em termos internacionais tem-se como referência a Declaração Mundial de Educação Para Todos, lançada em 1990, na Conferência de Jomtiem, na qual a educação é promulgada como direito fundamental de todos, mulheres e homens, de todas as idades, no mundo inteiro. Diversas foram suas metas (em forma de 10 artigos), dentre elas, destacamos: satisfazer as necessidades básicas de aprendizagem, colocando todas as pessoas em condições de aprender; propiciar meios adequados de aprendizagem; universalizar o acesso à educação e promover equidade (UNESCO, 1990).

A Declaração de Salamanca (1994), citada anteriormente, traz a ligação entre inclusão e necessidades educacionais especiais, fortalecendo seu processo e redefinindo papéis entre sujeitos e ambiente escolar. Isso porque a Declaração compreende que:

[...] as escolas deveriam acomodar todas as crianças independentemente de suas condições físicas, intelectuais, sociais, emocionais, linguísticas ou outras. (...) crianças deficientes, super-dotadas, crianças de rua e que trabalham, crianças de origem remota ou de população nômade, crianças pertencentes a minorias linguísticas, étnicas ou culturais (UNESCO, 1994, p. $3)$.

Por meio da Declaração de Salamanca fica clara, ainda, a posição de que todas as crianças devem, sempre que possível, aprender juntas, independente de quaisquer dificuldades e ou diferenças, sendo papel da escola reconhecer e responder às diversas necessidades com currículos apropriados, estratégias, recursos e arranjos organizacionais (UNESCO, 1994). Defende-se, neste documento, a importância de escolas com orientações 


\section{RevistAleph}

inclusivas tanto para o movimento de minimização de atitudes discriminatórias quanto para o de potencialização de comunidades mais acolhedoras.

Especificamente para a educação especial, a Convenção de Guatemala (1999) e a Convenção sobre Direitos das Pessoas com Deficiência (2007) também representam marcos importantes para o público alvo dessa modalidade. Ainda que a Declaração de Salamanca deixe claro o objetivo de uma educação de qualidade para todos, considerou-se necessário, para o público da educação especial, especificar e reforçar que pessoas com deficiência têm o mesmo direito das demais pessoas, não podendo, portanto, ser excluídas do sistema educacional sob alegação de deficiência. Ao passo que parece um retrocesso retomar tais questões em novo documento especificando apenas um grupo (reforçando a ideia da deficiência), é preciso compreender que fez e faz-se necessário essa luta por parte deste mesmo grupo, haja vista as inúmeras facetas excludentes as quais enfrentaram e enfrentam quando se fala do ensino regular.

Nacionalmente, a educação especial em uma perspectiva de inclusão é respaldada pela própria Constituição de 1988 , que aponta em seu artigo $6^{\circ}$ a educação como direito social e, portanto, de todos. No artigo 208, esta ideia é retomada, especificamente pensando o público alvo da Educação Especial, garantindo o atendimento educacional especializado às pessoas com deficiência, de preferência na rede regular de ensino (BRASIL, 1988). Além disso, é respaldada pela Lei Brasileira de Diretrizes e Bases da Educação Nacional, Lei no 9.394 de 1996, que denomina educação especial como modalidade da educação oferecida preferencialmente na rede regular de ensino, tendo os sistemas de ensino que assegurar currículos, métodos, recursos e técnicas que atendam às necessidades educacionais especiais dos educandos. Também na LDB (BRASIL, 1996) reforça-se a necessidade de formação especializada aos professores que atuam tanto no AEE quanto nas classes comuns, de modo a garantir a inclusão desses alunos no ensino regular.

Em um contexto de reconhecimento das diferenças e da diversidade na educação, assim como dos movimentos históricos políticos e sociais de lutas pela inclusão das pessoas com deficiência no ensino regular, a Política Nacional da Educação Especial na Perspectiva da Educação Inclusiva, de 2008, trouxe um contexto das políticas educacionais, nacionais e internacionais, que embasam a educação especial e o processo de inclusão em educação, assim como um diagnóstico sobre o campo em termos de matrículas, formação de 


\title{
RevistAleph
}

professores, acessibilidade arquitetônica. Objetivando acesso, participação e aprendizagem dos alunos público alvo da educação especial, a política orienta os sistemas educacionais a garantir:

\begin{abstract}
Transversalidade da educação especial desde a educação infantil até a educação superior; Atendimento educacional especializado; Continuidade da escolarização nos níveis mais elevados do ensino; Formação de professores para o atendimento educacional especializado e demais profissionais da educação para a inclusão escolar; Participação da família e da comunidade; Acessibilidade urbanística, arquitetônica, nos mobiliários e equipamentos, nos transportes, na comunicação e informação; e Articulação intersetorial na implementação das políticas públicas (BRASIL, 2008, p. 10).
\end{abstract}

A respeito do Atendimento Educacional Especializado, ele é definido como atendimento complementar e/ou suplementar ao ensino regular. Nesse sentido, "as atividades desenvolvidas no atendimento educacional especializado diferenciam-se daquelas realizadas na sala de aula comum, não sendo substitutivas à escolarização" (BRASIL, 2008, p.11). Desse modo, o AEE, de acordo com o Decreto 7.611 de 2011, desenvolve-se nas Salas de Recursos Multifuncionais (SRM) que são dotadas de equipamentos, materiais didáticos e recursos pedagógicos para o atendimento desse alunado.

Vale destacar, ainda, que a atuação do professor na educação especial, de acordo com a política nacional, prevê formação inicial e continuada, conhecimentos gerais para o exercício da docência e conhecimentos específicos da área. Esse requisito em termos de formação, demanda aos sistemas de ensino, investimentos capazes de suprir as necessidades dos educandos. A discussão com relação à formação especializada desses professores não é escassa.

Kassar (2012), por exemplo, questiona se, passados anos de processos e lutas em relação à educação das pessoas com deficiência, não estaríamos, ainda, com os mesmos problemas no que se refere à formação dos profissionais especializados e, portanto, ao atendimento desse público? A autora argumenta, ainda, que o histórico de exclusão, descaso e exploração que caracterizam a educação no Brasil impede de distinguir efetivamente se os problemas escolares decorrem da especificidade dos alunos com deficiência (questões de fato da educação especial) ou se constituem-se como problemas de toda a educação brasileira. Desse modo, falar em formação especializada para esse campo requer compreender antes a formação de professores em geral. Mantoan (2002, s/p.) já defendia também que para o 


\section{RevistAleph}

processo de inclusão, "mais urgente que a especialização é a formação inicial e continuada de professores para atender às necessidades educacionais de todos os alunos, no ensino regular".

Santos (2013), por sua vez, a partir da perspectiva omnilética de inclusão em educação, nos permite analisar o fenômeno formação de professores, seja inicial ou continuada, como um processo em que culturas, políticas e práticas de participação e aprendizagem se relacionam dialética e complexamente. Com outras palavras, a partir da perspectiva omnilética, poderíamos pensar a formação de professores para inclusão como um processo que depende do entrelaçamento e ressignificado ao mesmo tempo multidimensional e contraditório de crenças, acordos e ações, que envolvem olhares de variados sujeitos, grupos, instituições.

Por exemplo, essa perspectiva nos levaria a pensar políticas de formação continuada para professores que já estão nas redes federais, municipais, estaduais que contemplem um olhar ao mesmo tempo uno e múltiplo, ao mesmo tempo para diferença e para a diversidade, ao mesmo tempo para uma igualdade e para a equidade, que reconheça a complexidade e a dialeticidade existentes nesse processo que é a luta contínua pela redução de barreiras à aprendizagem e à participação, ou seja, pela inclusão. Processo infindável que compreende, ainda, a subjetividade existente, que deve ser considerada quando pensamos a dialética inclusão/exclusão, como nos aponta Sawaia (2014).

Tais autoras nos permitem refletir sobre a importância da formação continuada e das demandas em termos de uma educação para pensar as diferenças e a diversidade, já que a ideia de "não estar preparado" ou "não ter tido formação para isso" tem sido muitas vezes utilizada por professores e diretores para justificar o não atendimento de qualidade ao aluno com deficiência. Compreendendo a importância de uma educação que não reforce a ideia das deficiências, mas que potencialize as conquistas e que garanta aprendizagem e a participação de todos, quando defendemos que somente com a formação especializada poderá dar conta de um atendimento com qualidade, encontramo-nos em um embate, dialético e complexo.

Ora, se buscamos um olhar que contemple as diferenças e a diversidade, porém, que não as use para discriminar e/ou diferenciar, como pensar o ensino desses alunos? Seria, portanto, uma saída, uma formação inicial e continuada que contemplasse aspectos tanto das diferenças quanto da diversidade? Ou seja, "preparando" os professores para atuação em 


\section{RevistAleph}

contextos educacionais multifacetados, complexos e dinâmicos, fazendo-os compreender que as diferenças e a diversidade devem ser consideradas para potencializar e individualizar o ensino, porém, sem segregar e discriminar o aluno?

Algumas dessas questões apontadas esbarram na formação inicial dos professores (hoje oferecida em sua maioria nos cursos de Pedagogia, mas também nas demais licenciaturas) e na sua formação continuada. Nesse sentido, defendemos uma formação de professores (seja inicial ou continuada) que seja para a diversidade, compreendendo a importância da construção de culturas, do desenvolvimento de políticas e da orquestração de práticas que, ainda que em relação constantemente dialética e complexa, lutem pela eliminação de barreiras à participação e à aprendizagem de todos (SANTOS, 2008; 2009), por meio do diálogo entre teoria e prática, compreendendo que teoria e prática são aspectos distintos, mas que se complementam em relação um ao outro (SAVIANI, 2007, b), e ainda, que:

[...] a prática social constitui-se no principal mote do trabalho pedagógico, do qual emergirão, teórica e praticamente, as questões a serem problematizadas, os instrumentos para seu estudo e elucidação, e as ideias para aplicação à própria vida dos sujeitos envolvidos nesse processo, favorecendo, assim, a unidade teoria-prática (CRUZ, 2012, p. 156).

Nesse sentido, argumentamos por uma formação de professores para o enfrentamento dos desafios da educação para a diversidade e para a diferença em um diálogo profícuo entre teoria e prática, reconhecendo a interrelação entre elas. Como Santos, Santiago e Melo (2018) apontamos para a necessidade de uma formação, portanto, que desperte:

[...] potencial protagonista da ação docente para a elaboração de estratégias pedagógicas próprias, que, intencionalmente, promovam o debate, a identificação e a valorização das diferenças, assim como a eliminação das barreiras à inclusão em educação (p. 14).

Voltando ao embasamento das políticas educacionais para a educação especial na perspectiva da educação inclusiva, em 2015 foi lançada a Lei Brasileira de Inclusão da Pessoa com Deficiência - Estatuto da Pessoa com Deficiência, - (BRASIL, 2015), que visa assegurar e promover condições de igualdade e cidadania às pessoas com deficiência. Para a educação, 


\title{
RevistAleph
}

esta Lei, dentre suas orientações, reforça a não discriminação das pessoas com deficiência e seu direito à educação, a oferta de profissionais de apoio escolar, a formação e disponibilização de professores para o AEE.

Apesar de defendermos a construção - desde o chão da escola - de uma cultura de inclusão, pela qual concepções de acolhimento e participação devam perpassar as práticas educacionais, sabemos que por vezes, essa cultura também pode ser fruto de uma política maior, já que prerrogativas legais podem impor determinadas situações. No caso da LBI, ela tem provocado mudanças nas práticas das instituições de ensino, principalmente as particulares, no que tange à matrícula dos alunos com deficiência. Embora outras leis, citadas aqui, já preconizassem a matrícula desses alunos na rede regular, os casos de exclusão e não aceitação de matrícula, por exemplo, não foram poucos ao longo dos anos. Com essa Lei, especificamente, o que mudou foi a forma de responsabilização/criminalização na figura do gestor escolar, impactando, portanto, nas práticas das escolas em "aceitar" esse aluno.

Dessa forma, percebemos que a LBI veio complementar um movimento (de matrícula dos alunos com deficiências no ensino regular) que segundo Mantoan (2018) se formou a partir, principalmente, da PNEEPEI (BRASIL, 2008):

\begin{abstract}
Os dez anos de vigência da PNEEPEI foram essenciais para que as famílias, que antes só buscavam as escolas e classes especiais, passassem a matricular seus filhos com deficiência nas escolas comuns. Isso desestabilizou dirigentes e muitos profissionais de instituições especializadas (além de outros interessados) que se recusaram, ao longo dessa década, a abrir mão da escola especial e de outros locais de segregação para a formação (ad aeternum) de pessoas com deficiência (MANTOAN, 2018, p. 10).
\end{abstract}

Vale destacar que outras políticas mais específicas no campo da educação especial (como por exemplo a Política Nacional de Proteção dos Direitos da Pessoa com Transtorno do Espectro Autista, Lei $12.7664 / 2012$, conhecida como Lei do Autismo) e o próprio Plano Nacional de Educação 2014/2024 (BRASIL, 2014) - que tem em sua Meta 4 a proposta de universalizar até 2024 o acesso à educação básica, preferencialmente na rede regular, da população de 4 a 17 anos, público alvo da educação especial - também são importantes marcos para o campo da educação especial na perspectiva da inclusão. 


\section{RevistAleph}

\section{Discussão sobre a proposta de mudança: educação especial não mais na perspectiva de inclusão?}

Em abril de 2018, durante uma reunião organizada pela Secretaria de Educação Continuada, Alfabetização, Diversidade e Inclusão (SECADI, do Ministério da Educação - MEC) junto a um pequeno grupo de representantes de entidades voltadas a pessoas com deficiência e técnicos do MEC, foi divulgada, por meio de uma apresentação de slides, uma proposta de atualização da PNEEPEI (BRASIL, 2008). Sobre essa proposta, grupos de pesquisadores e professores engajados nos processos de inclusão manifestaram-se por meio de textos e outros movimentos, pontuando algumas questões.

Dentre as manifestações, foram feitas notas de repúdio como a da ANPEd (Associação Nacional de Pós-Graduação e Pesquisa em Educação), abaixo-assinado e elaboração de documentos escritos expondo comentários/críticas acerca da proposta do MEC, como o documento organizado por Maria Tereza Eglér Mantoan, professora doutora da Faculdade de Educação da UNICAMP.

No documento organizado por Mantoan, as autoras que com ela escreveram o texto (Cláudia Grabois, Cláudia Pereira Dutra e Meire Cavalcante) fizeram uma análise dos slides apresentados na reunião da SECADI, com o objetivo de dar subsídios para o debate sobre a atualização da política, defendendo primeiramente que:

[...] qualquer proposta de alteração dessa importante e inovadora Política só venha a ser apresentada, em forma de texto-base em consulta pública, após interlocução democrática com todas as esferas, entidades e pessoas interessadas e envolvidas com a educação inclusiva (MANTOAN, 2018, p. 4).

Isso porque, segundo as autoras, somente com slides e sem um debate democrático com a presença das esferas da sociedade envolvidas não se pode fazer qualquer tipo de modificação. A argumentação das autoras é de que não houve um texto formal (haja vista apresentação em forma de slides) e de que não houve discussão profunda, caracterizando processos não democráticos de tomada de decisão acerca do tema, não tornando, portanto, um processo que possa ser legitimado pela sociedade. Em resposta à postura do Conselho Nacional das Pessoas com Deficiência, que criticou o documento elaborado pelas autoras, Claudia Dutra (que fora Secretária da Educação Especial/MEC, de 2003 a 2013), escreveu um 


\section{RevistAleph}

texto que circulou pelas mídias e redes sociais, pontuando a falta de discussão sobre o "aprimoramento" da política.

Um fato grave, pois é sabido que tal proposta não é fruto da ampla discussão. E não adianta dizer que ir contra essa consulta pública fragiliza a democracia, quando o instrumento é usado como farsa para legitimar uma proposta que não teve interlocução com as posições divergentes (DUTRA, 2018, n.p) ) $^{98}$

A respeito dessa falta de debate, a ANPEd, com representação do Grupo de Trabalho de Educação Especial (GT 15) também se pronunciou, por meio de uma nota de repúdio:

[...] considerando o baixo índice de representatividade e aprovação popular do Governo Michel Temer; o fato desse governo estar no período final de seu mandato; estarmos em um ano eleitoral para Presidência da República, Congresso Nacional, Governos Estaduais e Assembleias Legislativas dos Estados da Federação, consideramos inapropriado e ilegítimo que uma revisão/atualização da Política de Educação Especial seja realizada nesse momento. Face ao exposto, a ANPEd repudia qualquer iniciativa de revisão da política de educação especial neste governo (ANPED, 2018, n.p). ${ }^{99}$

Outro argumento por Mantoan (2018) a respeito do movimento de "aprimoramento" na política, presente no documento, é que uma atualização seria desejável apenas se um estudo de monitoramento e/ou avaliação dos dez anos de implementação da política fosse realizado, comprovando real necessidade de atualizar ou modificá-la. Tendo em vista que não foi anunciado nenhum tipo de monitoramento e/ou avaliação das diretrizes da política, tal "atualização" pode ser considerada mais uma reforma, rasa e com dados pouco reais, comprometendo um avanço que foi dado com relação ao processo de inclusão na rede regular das pessoas com deficiências ao longo desses dez anos da PNEEPEI.

No documento com as críticas sobre a atualização da política nacional da educação especial aos slides da SECADI, onze foram os tópicos que as autoras desenvolveram seus argumentos a favor de um debate amplo e com participação de toda a comunidade envolvida no processo de inclusão, sendo eles: 1) Sobre a alegação de que a PNEEPEI não estaria de acordo com a lei; 2) Sobre o conceito de "Deficiência = AEE"; 3) Sobre a formação de professores de AEE; 4) Sobre Educação Especial e AEE; 5) Sobre as atribuições do professor de

\footnotetext{
${ }^{98}$ https://www.viomundo.com.br/denuncias/claudia-dutra-detona-postura-de-conselho-nacional-dos-direitosda-pessoa-com-deficiencia.html

${ }^{99}$ http://www.anped.org.br/news/nota-anped-sobre-possivel-revisao-da-politica-nacional-de-educacaoespecial
} 
AEE; 6) Sobre a definição de Educação Especial; 7) Sobre a alteração do público-alvo da Educação Especial; 8) Sobre a "identificação" do público-alvo da Educação Especial; 9) Sobre a família e o direito da criança à educação; 10) Sobre a metodologia do trabalho de AEE; 10) Sobre "resultados de aprendizagem". Na exposição e argumentação de cada item, retirados dos slides apresentados pela SECADI durante a reunião de atualização da política, as autoras pontuaram a falta de informação e definição de alguns termos importantes para o processo de inclusão e que já foram desenvolvidos e garantidos na PNEEPEI. Deixar brechas e possibilidades para diferentes interpretações é um risco ao processo de inclusão, um retrocesso em meio a tantas lutas. Outras pontuações foram referentes à falta de conhecimento da SECADI/MEC a respeito da própria política em vigência, visto que alguns conceitos foram desenvolvidos inadequadamente.

Por exemplo, a respeito do item 3 (Sobre a formação de professores de AEE), pelos slides o MEC afirmou que "Apenas $43 \%$ dos docentes atuando em turmas de AEE possuem curso de formação específica em Educação Especial." (Slide 3). Para Mantoan (2018), tal informação não pode ser justificativa para uma reforma da política, visto que $43 \%$ de professores com formação é um número bom, se pensarmos nos dez anos de desenvolvimento dessa política e, ainda, em todos os desafios de financiamento e de gestão por que passa a educação em todo o país.

De certo, a formação dos docentes ainda carece de investimentos, como o próprio Plano Nacional de Educação (2014-2024) prevê. As autoras argumentam que o foco do MEC deve ser em formação para a eliminação de barreiras no ambiente escolar, haja vista que o AEE não se resume às pessoas com deficiências, como a proposta dos slides pontuou. Chamam atenção, ainda, para a continuidade do "Programa Educação Inclusiva: Direito à Diversidade" cujo objetivo foi investir na formação de gestores e professores de sala comum e do AEE, pensando os problemas enfrentados in loco pelos sujeitos participantes.

Outra informação incoerente divulgada na proposta, por exemplo, foi o slide 4, que reduziu a educação especial ao $A E E$, sendo que a educação especial é muito mais do que o AEE e o atendimento nas Salas de Recursos Multifuncionais. Tal tendência, reforça o que acontecia no passado, onde não havia articulação entre professor da sala comum e professor do AEE - visão que foi modificada pela PNEEPEI em 2008:

Educação Especial é uma modalidade transversal, não substitutiva, que atua na escola como um todo, e fora dela também. Ela provê recursos, serviços e 
estratégias para acessibilidade. Um desses serviços é o AEE. Assim, é uma falácia afirmar que a Política atual "reduziu" a Educação Especial ao serviço do AEE. Se assim fosse, onde caberiam serviços outros, como profissional de apoio, guia-intérprete, professor e instrutor de Língua Brasileira de sinais, entre outros? Todos esses serviços são da Educação Especial. Cabe ao serviço de AEE organizar e articular todos os demais. Afirmar o contrário é confundir e desinformar a sociedade sobre as inovações pelas quais a Educação Especial passou e vem passando nos últimos anos, em decorrência das inovações da PNEEPEI (MANTOAN, 2018, p. 18).

Em diálogo com essa "redução da educação especial ao AEE e à SRM", a proposta de atualização da política ainda afirma que a PNEEPEI sobrecarregou o professor do AEE. Ora, se tal fato vem ocorrendo, não é o que a política atual preconiza. Ao contrário, a mesma prevê que o ensino do estudante com deficiência seja na sala regular, com o professor da sala regular, sendo o professor do AEE responsável por, no contraturno, desenvolver potencialidades, trabalhar com foco na superação de algumas dificuldades do aluno, desenvolver recursos de acessibilidade, entre outros, e não ensinar o conteúdo que deve ser ensinado na sala regular. Segundo Mantoan (2018) a "PNEEPEI aponta estratégias para o desenvolvimento inclusivo da escola. O que se espera do MEC é o fortalecimento dessas estratégias" (p. 21).

A proposta de "aprimoramento" da política apresentada, assim, nada tem a ver com uma "atualização", pois se colocou mais como um retrocesso do que um avanço, o que causou impacto negativo às instituições, pesquisadores e outros sujeitos envolvidos nas questões dos processos de inclusão em educação no país. Ressaltamos três pontos apresentados na "nova proposta" demonstram seu caráter retrógrado, segundo o documento de análise e manifesto sobre a "reforma" da política de 2008 (MANTOAN, 2018).

O primeiro deles aponta uma tentativa de definir educação especial como uma modalidade de educação escolar. Já conquistamos, pela Convenção sobre os Direitos das Pessoas com Deficiência (BRASIL, 2009) e a Lei Brasileira de Inclusão (BRASIL, 2015), que Educação Especial é modalidade de ensino que perpassa todos os níveis da educação. No momento em que se propõe a retirada da ideia de modalidade transversal, trazendo de volta o termo "escolar", sem menção ao AEE, abre-se uma brecha para que seja interpretada a possibilidade de se retornar a educação especial a um papel substitutivo à escola comum, como um sistema paralelo, legitimando exclusões, como já fora interpretada na LDB de 1996, 


\section{RevistAleph}

que também, ainda limitada, apresenta o termo modalidade "escolar" ao referir-se à educação especial.

Vale ressaltar que a preocupação com as leis e os termos que são nela "colocados" reflete a possibilidade de interpretações que elas podem apresentar, dependendo do contexto da prática, de sua aplicabilidade. Isso porque, quando falamos de política, não podemos deixar de compreender que seus movimentos não são lineares e se traduzem em processos complexos. Quando pensamos em políticas, é preciso reconhecê-las como acordos e intenções que não se findam em sua formulação somente, mas se traduzem em suas práticas e efeitos, dependendo, portanto, dos sujeitos e das interpretações que esses sujeitos a elas dão e como as colocam, portanto em prática, como propõem Ball \& Mainardes (2011).

Essa possibilidade de interpretação para uma educação especial substitutiva, associada ao segundo ponto da proposta, que é o de envolvimento da família e do estudante no processo decisório (sem negar a importância da parceria entre escola e família), é preocupante. Isso porque abre-se mais uma porta para diferentes interpretações, inclusive, a de que seria, portanto, legítima, a privação da pessoa com deficiência da participação e da aprendizagem no ambiente do ensino regular. Por fim, destacamos como terceiro ponto um que corrobora com a ideia de que esta proposta apresentada seja uma reforma retrógrada e não uma atualização: a retirada do termo "na perspectiva da educação inclusiva", do nome da política.

A análise e as críticas desenvolvidas no documento de Mantoan (2018), acerca dos slides da SECADI, juntamente com o movimento da sociedade e outras instituições que pensam e fazem a inclusão acontecer, fizeram com que o MEC voltasse atrás na proposta apresentada. No dia 6 de julho de 2018 foi lançado pela SECADI/MEC um Ofício Circular aos reitores dos Institutos Federais de Educação, Ciência e Tecnologia chamando a comunidade acadêmica para participar de uma consulta pública, na qual os representantes pudessem colaborar com a proposta de atualização da Política Nacional da Educação Especial na Perspectiva da Educação Inclusiva. As colaborações foram realizadas até dia 20 de julho (ou seja: apenas 14 dias de consulta a todo o país), tendo o MEC divulgado um documento, novamente em formato de apresentação de slides, com as contribuições da comunidade sobre a política. 
Uma vez mais, a nova versão da política não agradou e causou polêmica e movimentos de repúdio. Desta vez, o destaque ficou a cargo da Associação Brasileira de Pesquisadores em Educação Especial (ABPEE). A Associação, reunida em Assembleia em 16 de novembro de 2018, durante o VIII Congresso Brasileiro de Educação Especial e XI Encontro Nacional de Pesquisadores da Educação Especial (XI ENPEE) e com o apoio de outras entidades (Associação Nacional de Pós-graduação e Pesquisa em Educação - ANPED; Associação Nacional pela Formação dos Profissionais da Educação - ANFOPE; e Fórum Nacional de Coordenadores dos Núcleos de Acessibilidade das Instituições Públicas de Educação Superior, Profissional e Tecnológica - IPESPTec), emitiu importante documento contrário à atualização da nova versão da política. Tal documento foi lido por uma representante escolhida pela Assembleia, professora Mônica Pereira dos Santos, ao Conselho Nacional de Educação, em Plenária pública que ocorreu em 19 de novembro do mesmo ano.

No texto, 7 foram os motivos elencados para o posicionamento contrário:

1. A proposta não é fruto de participação democrática. Consulta pública não é debate e interlocução. Queremos diálogo verdadeiro com a população, profissionais e sociedade civil organizada.

2. A proposta de atualização não se embasa no conceito de deficiência constituído na Convenção sobre os Direitos das Pessoas com Deficiência, que hoje é parte de nossa Constituição Federal.

3. O paradigma inclusivo, garantido na Constituição Federal, prevê ingresso e permanência com qualidade em classes comuns de escolas regulares. Liberdade de escolha não significa retornar às escolas especiais, mas garantir participação da população no processo educacional.

4. O Atendimento Educacional Especializado não é assistência tecnológica. Ele orienta a construção conjunta e colaborativa do plano de AEE, com base na leitura das barreiras existentes para a educação escolar.

5. A Convenção sobre os Direitos das Pessoas com Deficiência e a Lei Brasileira de Inclusão da Pessoa com Deficiência garantem acesso pleno ao currículo (Inciso III, Art. 28) e adaptações razoáveis (§3‥, Art. 54), o que é incompatível com a diferenciação curricular.

6. A ausência de diretrizes que garantam a Educação Especial na formação inicial do professor de classe comum;

7. A proposição de escolas especiais e classes especiais como parte das diretrizes, aspecto já superado na atual política.

O ano de 2018 terminou com um retorno ao "silêncio" a respeito do tema, tendo em vista o fim do processo eleitoral presidencial, a vitória de Jair Bolsonaro, a transição governamental e outras providências que deveriam ser tomadas nos próximos meses, o que 


\section{RevistAleph}

fez com que as movimentações no sentido de se "atualizar" a política fossem interrompidas até meados de 2019.

Com o início do governo Bolsonaro, em 2019, algumas alterações têm sido feitas com relação ao próprio governo, ministérios e secretarias. Com a justificativa de redução de custos, de 29 ministérios do governo anterior, passou-se a ter 22 e, assim, algumas secretarias fechadas, suprimidas e/ou ligadas a outras secretarias.

No Ministério da Educação, havia a Secretaria de Educação Continuada, Alfabetização, Diversidade e Inclusão (SECADI/MEC), cujo objetivo era assegurar o direito à educação com qualidade e equidade, por meio de políticas públicas voltadas para a inclusão social. A mesma foi extinguida pelo Decreto no 9.465, de 2 de janeiro de 2019 (posteriormente revogado pelo Decreto $n$ o 10.195 , de 30 de dezembro de 2019). Tal fato nos remete a um recuo grande no campo dos direitos educacionais, que vai de encontro às propostas de reconhecimento da diversidade e da inclusão no processo educacional.

Com a extinção da SECADI, foi criada Secretaria de Modalidades Especializada, cuja atribuição é:

[...] planejar, orientar e coordenar, em articulação com os sistemas de ensino, políticas para a educação do campo, para a educação especial de estudantes com deficiência, transtornos globais do desenvolvimento e altas habilidades ou superdotação, na perspectiva da educação inclusiva, e para a valorização das tradições culturais brasileiras, inclusive dos povos indígenas e de populações em áreas remanescentes de quilombos.

Algumas pesquisadoras da área, quando entrevistadas pelo site "De Olho nos Planos" sobre a extinção da SECADI, apontaram que embora não seja possível avaliar tão rapidamente o impacto dessa mudança, a preocupação principal é da orientação que ela terá, tendo em vista que os anos anteriores de luta foram em prol de um educação inclusiva, como diz Capellini (2019). Por sua vez, Mantoan (2019) aponta que mais importante do que identificar qual órgão será responsável pelas ações da educação especial, é que ele mantenha a perspectiva inclusiva.

Concordando com as pesquisadoras, destacamos que a SECADI era responsável pela formação de professores, tanto do Atendimento Educacional Especializado, quanto da inclusão em seu sentido amplo. Nesse sentido, apesar das mudanças de nome/configurações de secretarias e departamentos, importa é que os programas e políticas de formação inicial e 


\section{RevistAleph}

continuada mantenham suas verbas e, assim, ações, tendo em vista uma educação que preze pela aprendizagem e participação de todos.

No que tange à formação inicial e continuada Santos, Santiago e Melo (2015, p. 110) reforçam que "as políticas inclusivas tratam-se de uma dimensão que garante que a inclusão permeie todos os planos da escola e envolva todos os seus atores". Por essa perspectiva, compreende-se que é fundamental que a política nacional seja não apenas absorvida, mas ressignificada nas culturas, políticas e práticas docentes e escolares. Caso contrário, a sua implementação, ou seja, o que caracteriza a dimensão da prática da política em si, torna-se ineficiente.

Apesar da comoção da sociedade que se deu em 2018 pela falta de consulta, participação e avaliação com relação às possíveis modificações na política, em agosto de 2019, o governo em um evento, no Conselho Nacional de Educação, intitulado "Inclusão Educacional: políticas, caminhos e possibilidades" e convocado pela relatora da Comissão que trata a Revisão das Diretrizes Curriculares Nacionais para a Educação Especial anuncia a continuação da atualização da Política Nacional da Educação Especial na Perspectiva da Educação Inclusiva.

Tal anunciação foi mais uma vez motivo de comoção e de respostas, via cartas e manifestos advindos de organizações da sociedade civil, laboratórios de pesquisas, universidades e grupos envolvidos com a educação especial, visto que mais uma vez tratouse de um evento com pouca representatividade e, assim, pouca participação da sociedade e daqueles que efetivamente se envolvem com a qualidade da educação especial no país (universidades, laboratórios de pesquisas, membros de organizações, famílias e os próprios alunos da educação especial).

De acordo com Federação Down - que foi convocada para estar presente em tal evento e que realizou uma corrente a favor da PNEEPEI reivindicando a participação democrática - em uma carta, junto a outras entidades, as reformulações feitas pelo MEC, na verdade expõem uma mudança de perspectiva sobre a política de inclusão no país. A Federação viu como problemática a falta de pluralidade presente no evento, além de ter considerado insuficiente o tempo dado para divulgar a consulta e permitir plena participação da sociedade, tendo em vista o extenso trabalho e tempo que a discussão cuidadosa do tema requereria. Neste sentido, considerou que a audiência tratou-se de ação em sentido contrário 


\section{RevistAleph}

ao inclusivo e considera-se que o governo federal está retrocedendo no cumprimento do direito à educação das pessoas com deficiência.

Nesse sentido, o grupo solicitou ao Ministério da Educação que torne sem efeito qualquer decisão que tenha sido tomada ou surgido a partir do evento, além de pedir um agendamento de reunião com especialistas do Ministério da Educação, centros de pesquisa e entidades representativas, em ato democrático. Tal documento foi assinado por entidades e instituições como: Associação de Pais e Amigos do Down (ASPAD), Câmara Paulista para Inclusão das Pessoas com Deficiência no Mercado de Trabalho Formal, Centro de Educação Especial Síndrome de Down (CEESD), Fórum Permanente de Educação Infantil do Espírito Santo (FOPEIES), Laboratório de Estudos e Pesquisas em Ensino e Diversidade (LEPED/Unicamp) , Laboratório de Pesquisa, Extensão e Apoio Educacional em Linguagem e Educação Especial (LALEDE/USP), Instituto de Pessoas com Síndrome de Down do Pantanal (PESDPAN), entre outros.

Ainda em 2019 mais um ponto preocupante para a educação especial no Brasil surge. O governo de Jair Bolsonaro propõe mudanças na Política Nacional de Educação Especial para 2020, visando alternativas de ensino para alunos com deficiência intelectual ou física, Transtorno do Espectro Autista (TEA) e superdotação de modo que o ensino regular não seja a única opção a esses alunos. De acordo com Bilches (2020), do jornal Gazeta do Povo, a ideia é que caberá a família, assim como a escola, escolher o melhor lugar para o aluno, se é a sala de aula regular, a classe especial, ou ainda se seria mais adequado a transferência para uma escola especial.

De acordo com a diretora de Acessibilidade, Mobilidade, Inclusão e Apoio a Pessoas com Deficiência do Ministério da Educação (MEC):

É preciso promover a inclusão plena desse público. Temos que oferecer ambientes favoráveis para o desenvolvimento pleno das potencialidades das pessoas. E, muitas vezes, esse ambiente não é o da escola comum. Precisa ser um ambiente que vai trabalhar em função das especificidades da pessoa, das singularidades dela. Então nosso foco está na pessoa, naquilo que é o melhor para ela.

Vale ressaltarmos o quão problemático essa mudança pode vir a ser. Isso tendo em vista a possibilidade de que tal movimento venha a segregar esses alunos com deficiência, além de os privar do contato e interação com os outros alunos, visando a heterogeneidade 


\section{RevistAleph}

de uma turma como ponto fundamental para o desenvolvimento dos alunos com ou sem deficiência.

Argumentamos que um processo sem diálogo sobre modificações de políticas, como a "atualização" da PNEEPEI - que, mesmo sem ser perfeita, trouxe, em comparação às anteriores e ao longo de seus dez anos, avanços significativos (em termos principalmente de legitimação da participação e da aprendizagem sem discriminações, diferenciações e, consequentemente, exclusões) para o processo de inclusão em educação do público alvo da educação especial - deve ser motivo de preocupação das entidades e instituições envolvidas com o tema. Nesse sentido, enfatizamos a importância do desenvolvimento coletivo e contínuo de políticas, culturas e práticas de inclusão em seu sentido amplo, no que diz respeito à educação. Culturas, políticas e práticas mais democráticas, menos excludentes e discriminatórias e que fortaleçam a aprendizagem e a participação de todos dentro da escola.

\section{Considerações Finais}

Discutir sobre temas da educação na contemporaneidade é desafio permanente dos professores, pedagogos e pesquisadores brasileiros. Neste artigo trouxemos à luz do debate uma questão fundamentalmente problemática da educação, a educação especial, na busca sobretudo de tecer comentários a respeito dos embates atuais diante da proposta de modificação da Política Nacional da Educação Especial na Perspectiva da Educação Inclusiva, que como colocado aqui caracteriza-se mais como uma reforma imposta do que uma atualização retrógrada proposta em discussão para a sociedade.

Salientamos a importância dos movimentos da sociedade no posicionamento contra toda e qualquer modificação a política que não tenha sido realizada, não apenas sob consulta, em colaboração e participação dos sujeitos envolvidos no processo de inclusão das pessoas com deficiência no ensino regular. Além do debate necessário, argumentamos pela necessidade de reflexão sobre a proposta realizada pelo MEC que tem a intenção, implicitamente colocada na apresentação dos slides, de retroceder anos de lutas e embates a favor da aprendizagem e participação de todos, juntos, na escola.

Finalizamos, ainda, com um chamado de atenção para os discursos com relação à formação (inicial e continuada) de professores. Não podemos permitir que "não estar preparado", "não ter formação específica" ou "não ter formação prática, somente teórica", 


\section{RevistAleph}

sejam justificativas para a exclusão desse alunado na educação. Há que se pensar e, mais do que isso, investir, portanto, em formações para a diversidade, contemplando a minimização de barreiras à aprendizagem e à participação de todos e de cada um, que permitam assim a compreensão de que a educação é campo de lutas, disputas, saberes e conhecimentos, e que, como tal, precisa contemplar a todos.

\section{Referências}

ANPED. Nota ANPEd sobre possível revisão da Política Nacional de Educação Especial. Disponível em: http://www.anped.org.br/news/nota-anped-sobre-possivel-revisao-da-politica-nacional-deeducacao-especial. Acesso em 25 jul. de 2018.

BALL, S. J \& MAINARDES, J. Políticas Educacionais: questões e dilemas. São Paulo: Cortez, 2011.

BILCHES, William. MEC vai mudar política para alunos com deficiência; saiba o que deve ser alterado. Gazeta do Povo. Curitiba, 11/12/2019. Educação. Disponível em:

https://www.gazetadopovo.com.br/educacao/mec-vai-mudar-politica-para-alunos-com-deficienciasaiba-o-que-deve-ser-alterado/ Acesso em: 23/03/2020.

BOOTH, T.; AINSCOW, M. Index para Inclusão: desenvolvendo a aprendizagem e a participação nas escolas. 3. ed. Tradução: Mônica Pereira dos Santos. 2012.

BRASIL. Constituição da República Federativa do Brasil. Brasília: Senado. 1988. Disponível em: http://www.planalto.gov.br/ccivil_03/constituicao/constituicaocompilado.htm. Acesso em: jul/2018.

BRASIL. Política Nacional de Educação Especial na Perspectiva da Educação Inclusiva. Documento elaborado pelo Grupo de Trabalho nomeado pela Portaria no 555/2007, prorrogada pela Portaria no 948/2007, entregue ao Ministro da Educação em 07 de janeiro de 2008.

BRASIL. Decreto n. 7.611, de 17 de novembro de 2011. Dispõe sobre a educação especial, o atendimento educacional especializado e dá outras providências. Lex: Presidência da República/Casa Civil/Subchefia para Assuntos Jurídicos. Brasília, nov. 2011.

BRASIL. Lei de Diretrizes e Bases da Educação Nacional: Lei no 9.394, de 20 de dezembro de 1996. Disponível em: https://www.planalto.gov.br/ccivil_03/Leis/L9394.htm. Acesso em: 27 nov. 2016.

BRASIL. Lei no 12.764, de 27 de dezembro de 2012. Institui a Política Nacional de Proteção dos Direitos da Pessoa com Transtorno do Espectro Autista; e altera o § 3o do art. 98 da Lei no 8.112, de 11 de dezembro de 1990. 2012

BRASIL. Câmara dos Deputados. Plano Nacional de Educação 2014-2024. Câmara dos Deputados, Edições Câmara, Série Legislação, n. 125, Brasília, 2014.

BRASIL, 2015, Lei n. 13.146, de 6 de jul. de 2015. Lei Brasileira de Inclusão da Pessoa com Deficiência. Disponível em: http://www.planalto.gov.br/ccivil_03/_Ato2015-

2018/2015/Lei/L13146.htm. Acesso em: 25 jul 2018. 
BRASIL, 2019. Decreto no 9.465, de 2 de janeiro de 2019. Disponível em: http://www.planalto.gov.br/ccivil_03/_ato2019-2022/2019/Decreto/D9665.htm. Acesso em: 20 mar. 2020.

BRASIL, 2019. Decreto no 10.195, de 30 de dezembro de 2019. Disponível em: http://www.planalto.gov.br/ccivil_03/_ato2019-2022/2019/Decreto/D10195.htm\#art8. Acesso em: 20 mar. 2020.

CAPELLINI, V. Educação Especial. Entrevista em De Olho nos planos. Disponível em: http://www.deolhonosplanos.org.br/100-dias-de-bolsonaro-secadi/. Acesso em: 20 mar. 2020.

CRUZ, G. B. da. Teoria e prática no curso de Pedagogia. Educação e Pesquisa, São Paulo, v. 38, n. 1, p. 149-164, 2012.

DUTRA, C.. Em defesa da educação inclusiva. Arquivo Pessoal. 2018. Disponível em: https://www.viomundo.com.br/denuncias/claudia-dutra-detona-postura-de-conselho-nacional-dosdireitos-da-pessoa-com-deficiencia.html. Acesso em: 25 jul. 2018.

FERREIRA, M. M.; BOZZO, F. E. F. EDUCAÇÃO INCLUSIVA: Inclusão de crianças com Síndrome de Down no ciclo I do ensino fundamental. São Paulo: Lins Editora, 2009.

KASSAR, M. C. M.. Educação especial no Brasil: desigualdades e desafios no reconhecimento da diversidade. Educ. Soc. [online]. 2012, vol.33, n.120, pp.833-849.

PLETSCH, M. D.. Repensando a inclusão escolar: diretrizes políticas, práticas curriculares e deficiência intelectual. Rio de Janeiro: NAU/EDUR, 2010.

SANTOS, M. P. dos. Educação inclusiva: redefinindo a educação especial. Ponto de Vista, Florianópolis, n. 3/4, p. 103-118, 2002.

SANTOS, M. P. dos. Inclusão. In: SANTOS, M. P dos; FONSECA, M. P; MELO, S. C. (org.) Inclusão em Educação: diferentes interfaces. Curitiba: Editora CRV, 2009.

SANTOS, M. P. dos. Inclusão em Educação: Uma visão geral. In: SANTOS, M. P. dos; PAULINO, M. M. Inclusão em Educação: Culturas, políticas e Práticas. 2. ed. São Paulo: Cortez, 2008.

SANTOS, M. P. dos.Dialogando sobre inclusão em educação: contando casos (e descasos). 1. ed. Curitiba, PR: CRV, 2013.

SANTOS, M. P. dos; SANTIAGO, M. C. ; MELO, S. C. . Formação de Professores para o atendimento educacional especializado: políticas e práticas instituintes de inclusão. Aleph (UFF. Online), v. XII, p. 103-128, 2015.

SANTOS, M. P. dos; SANTIAGO, M. C. ; MELO, S. C. . Formação de professores frente ao desafio da diversidade pela lente omnilética: culturas, políticas e práticas em movimento. Linhas (Florianópolis. Online), v. 19, p. 11-29, 2018.

MANTOAN, M. T. E. (org.). Em defesa da Política Nacional da Educação Especial na Perspectiva da Educação Inclusiva: análise e manifestação sobre a proposta do Governo Federal de reformar a PNEEPEI (MEC/2008). 2018. 


\section{RevistAleph}

MANTOAN, M. T. E. Educação Especial. Entrevista em De Olho nos planos. Disponível em:

http://www.deolhonosplanos.org.br/100-dias-de-bolsonaro-secadi/. Acesso em: 20 mar. 2020.

SAVIANI, D.. Epistemologias e teorias da Educação no Brasil. Pro-posições, v.18, n. 1 (52) - p. 15-27, jan./abr. 2007a.

SAVIANI, D.. Pedagogia: o espaço da educação na universidade. Cadernos de Pesquisa, v. 37, no 130, p. 99-134, jan. 2007b.

SAWAIA, B. (Org.). As artimanhas da Exclusão - análise psicossocial e ética da desigualdade social. 14ạ edição. Petrópolis: Vozes, 2014.

UNESCO. Declaração Mundial sobre Educação para Todos: satisfação das necessidades básicas de aprendizagem. Jomtien, Tailândia, 1990.

UNESCO. Declaração de Salamanca. Conferência Mundial sobre Necessidades Educativas Especiais: acesso e qualidade. Salamanca, Espanha, 1994.

Data do envio: $13 / 04 / 2020$

Data do aceite: $22 / 04 / 2020$ 